REIMPRESIÓN

Rev Chil Salud Pública 2015;

Vol 19 (2): 207-209

\section{¿HACIA DÓNDE VA LA MEDICINA SOCIAL? ${ }^{(i)}$}

Existen innumerables polémicas y opiniones controvertidas sobre las acciones que se están desarrollando en el área económica en la denominada "vía chilena de transición al socialismo". La recuperación para Chile de sus riquezas básicas, la estatización de la banca, la profundización de la reforma agraria, la determinación de las áreas de la propiedad, mixta y privada, etcétera, van señalando un camino orientado básicamente a modificar las relaciones de producción y la propiedad de los medios de producción. Se podrá estar a favor o en contra de determinadas medidas concretas, de mayor o menor aceleración del proceso, pero la opinión pública cada vez más está dejando atrás su tradicional "neutralidad" sobre estos aspectos tan vitales del desarrollo de nuestro país. Los medios de comunicación de masas tampoco están quedando al margen y según el cristal óptico de sus propiedades y equipos directivos, están promoviendo una acelerada discusión del proceso que Chile está viviendo en el campo económico. Desde la llegada al Gobierno por elección popular del primer Presidente marxista y de las fuerzas sociales y políticas de la Unidad Popular.

En contraste con la relativamente rápida toma de conciencia de los problemas del área económica, hay un desconocimiento mayor y una pasividad aparente en lo relacionado al área social. Educación, salud, vivienda, seguridad social y otros son analizados con menor profundidad y en forma más esporádica, con alzas bruscas cuando ocurren situaciones cotidianas “escandalosas”. Explosivas, alarmantes o violentas. El fenómeno de la “cultura” y los aspectos sociales del desarrollo revisten tal importancia, aunque para muchos estén aún en el inconsciente, que no podrá haber auténticos cambios en las estructuras económicas sin profundas modificaciones culturales y sociales. Existen relaciones inseparables e interdependientes entre la infra y la superestructura que obligan a enfocar la revolución como un todo integral en sus aspectos económicos, sociales y culturales.

\section{LA SALUD, ¿UN MITO INTOCABLE?}

Los temas sobre "salud", "atención médica”, "medicina social” están vivos y latentes en la población. La vida y la muerte no son hechos circunstanciales ni periféricos. Sin embargo, se analizan solo superficialmente, sin darles la real transcendencia que tienen. La procesión va por dentro. Hay ruidos subterráneos que anuncian que algo podría pasar, que el volcán podría estallar, que el despertar puede ser mucho más rápido y más violento que lo que se podría imaginar. Tal vez, aún persiste gran parte del mito de no tocar lo que parece intocable. Pero la historia nos enseña que los procesos siguen su propio dinamismo en el contexto global, que los diques de contención no

(i) Patricio Hevia, médico pediatra, salubrista, ha desempeñado altos cargos directivos en OPS, fue jefe de la Unidad Patrimonial Cultural del Ministerio de Salud, y actual Director de la Casa de la Cultura del Colegio Médico. Ha desplegado una importante labor en el rescate patrimonial de la historia médica y cultural del país. Nos ha parecido de interés y actualidad el texto publicado en la revista Mensaje al inicio del Gobierno de Salvador Allende, en el cual se releva la presencia política de la opinión pública, luego ahogada y adormecida para emerger con fuerza 40 años después. Notorio, asimismo, es que si bien el presupuesto de salud ha subido al 7\% del PNB, se mantiene aún hoy la disparidad básica: la mitad de esos recursos son del sector público, correspondiendo el resto al sector privado que solo atiende entre un 20 a un $25 \%$ de la población. Publicado con autorización expresa del director de Revista Mensaje, Antonio Delfau S.J. 
existen. La conciencia del derecho a la salud que hasta hace pocos años casi no existía en la gran mayoría de los trabajadores, se va adquiriendo a un ritmo acelerado. El acceso a la salud ya no se pide como una dádiva: se exige, cada vez más con más fuerza y con más violencia.

Hay muchas formas de enfocar el tema. Muchos antecedentes que podrían comunicarse. En esta oportunidad nos limitaremos a señalar solo algunos hechos y plantear varias interrogantes. No olvidemos que en nuestra sociedad capitalista uno de los valores que tiene mayor importancia es el valor "dinero". Y en salud hay muchos intereses creados, igual que en justicia, en educación y en otros sectores del área social.

\section{SERVICIO NACIONAL DE SALUD, INTENTO COHERENTE DE MEDICINA SOCIAL}

La creación del Servicio Nacional de Salud el 8 de agosto de 1952, mediante la Ley $\mathrm{N}^{\circ} 10.383$, significó un hito de transcendental importancia para la Medicina Social en Chile, con proyecciones en toda Latinoamérica. Surgió de nuestra propia realidad. No fue copia de ninguna otra institución similar en el mundo. Se basó en los antecedentes históricos existentes, aprovechando experiencias extranjeras, especialmente de la URSS y de Gran Bretaña. Han pasado 19 años, cinco gobiernos de las más variadas tendencias y el SNS sigue presente en gran parte del territorio nacional, atendiendo a una población beneficiaria estimada en aproximadamente el $70 \%$ de la población total, excepto para algunas acciones (como vacunaciones) que abarcan al $100 \%$ de la población del país. Sin embargo, estos años no han sido fáciles y en la actualidad podemos decir que, con raras excepciones, existe un desprestigio a nivel de las bases populares que solo transitoriamente es borrado cuando se comprueba su fuerza solidaria en las grandes emergencias del país (temporales, terremotos, etc.). Se dice reiteradamente que la atención médica es mala, inhumana, incompleta y tardía; se producen verdaderos enfrentamientos entre funcionarios del SNS y pobladores beneficiarios; se critica su lenta burocracia, la falta de médicos y otros profesionales y téc- nicos de salud. Cuando un niño o una madre es rechazada, cuando se le niega la atención por no haber capacidad, se produce un dolor profundo y una rebeldía de impotencia: muchas veces de eso depende la vida o la muerte.

\section{SISTEMAS DE ATENCIÓN MÉDICA Y SUS CONTRADICCIONES CLASISTAS}

Por otra parte la Ley 16.781, de mayo de 1968, denominada "Ley de Medicina Curativa" hace una clara diferencia, de tipo esencialmente "clasista" entre empleados y obreros. A los primeros se les ofrece a través del Servicio Médico Nacional de Empleados (SERMENA), pagando directamente con un bono moderador de bajo costo, la medicina de libre elección; a los segundos, se les obliga solo al sistema de la medicina funcionaria. ¿Qué es mejor? ¿Por qué existen tipos tan diversos de atención médica cuya frontera es solo la categoría de "empleado" u "obrero"? ¿Qué ventajas y desventajas tienen ambos sistemas? ¿Cuál es el futuro de ellos?

Aparte del Servicio Nacional de Salud (para obreros afiliados al Servicio de Seguro Social e "indigentes") y del SERMENA (para empleados públicos y particulares), existen innumerables instituciones públicas de salud que están dispersas e incluso dependen de otros ministerios diferentes a Salud. Ejemplos de ellos: Hospital de Carabineros (Ministerio del Interior), Hospital Militar (Defensa), Hospital Naval (Defensa), Hospital José Joaquín Aguirre (Educación), Servicio Médico de Prisiones (Justicia), Instituto Médico Legal (Justicia), etcétera.

El dinero en último término proviene de los contribuyentes. Sin embargo, los recursos se aprovechan en forma diferente y se establecen muchos servicios paralelos. Uno de los mayores peligros potenciales es que SERMENA empiece a construir hospitales y consultorios propios en diversas ciudades y pueblos de Chile. ¿Tendremos los recursos suficientes para sostener dos redes paralelas de establecimientos de salud a nivel de todo el territorio nacional? ¿Es esencial la diferencia entre "obreros y "empleados" hasta tal punto que aparecen como clases antagónicas? ¿Cuáles serían las ventajas y las desventajas 
de un Servicio Único Nacional de Salud? Esta y otras interrogantes solo podrían tratar de responderse en artículos posteriores, siempre que tengan real interés.

\section{DESPROPORCIÓN ENTRE ACCIONES, RECURSOS Y GASTOS EN SALUD}

En la actualidad, la mayor parte de las acciones de salud se realizan a través del Servicio Nacional de Salud (SNS) que paradójicamente está crónicamente desfinanciado. Para ello, el SNS dispuso en 1970 de 48.344 funcionarios, de los cuales 5.862 eran médicos, dentistas y farmacéuticos; 5.071 correspondían a otros profesionales y técnicos de la salud (enfermeras, matronas, asistentes sociales, nutricionistas, etc.) y 37.411 a personal auxiliar, administrativo y de servicio. De las 10.043.756 consultas médicas registradas en 1970, 8.915.902 las efectuó el SNS (88,7\%). Con las consultas realizadas por enfermeras y matronas, entrega de leche, recetas y prescripciones despachadas, etcétera, es aún más notable el predominio del SNS en relación a otras instituciones públicas y particulares de salud. Igual situación sucede con las camas de hospitalización, ya que del total de 35.932 camas existentes en 1970 en todo el país, 33.611 pertenecían al SNS (93,5\%).

Ante esta realidad objetiva, los estudios realizados desde hace años sobre distribución del gasto en salud en Chile, demuestran reiteradamente que más del 50\% de él se efectúa en el sector privado que cubre a una minoría de la población. En 1968 el país gastó 2.669 millones de escudos en servicios de salud; equivalentes al 6,2\% del Producto Nacional Bruto (PNB). Del total, 1.076 millones de escudos $(40,3 \%)$ correspondieron al sector público (2,5\% del PNB) y 1.593 millones de escudos $(59,7 \%)$, al sector privado $(3,7 \%$ del PBN). Destaca además del predominio del gasto en el sector privado, el alto gasto que se realiza en el rubro "farmacia" ( $35 \%$ del total) donde la diferencia entre ambos sectores es extraordinariamente grande $(4,5 \%$ en el sector público versus $55 \%$ en el sector privado).

Las proyecciones inmediatas y a largo plazo no pueden ser indiferentes para la pobla- ción consciente del país. La demanda de las prestaciones de salud crece a ritmo acelerado, el egreso de profesionales calificados de salud aumentan a ritmo muy lento y la distribución del número total de profesionales que egresa cada año es injusta, ya que en una competencia entre diferentes instituciones públicas de salud con remuneraciones desiguales y las instituciones privadas con remuneraciones necesariamente mayores; sale directamente perjudicado el SNS y por tanto la mayoría de los trabajadores del país. Muchos médicos, enfermeras, matronas y otros profesionales rechazan su ingreso al SNS, que tiene la obligación técnica y moral de cubrir las necesidades crecientes de salud de los grandes sectores rurales y agrupaciones suburbanas marginales.

\section{DEMOCRATIZACIÓN Y DESCENTRALIZA- CIÓN: UN PASO HACIA LA UNIDAD}

Finalmente, es necesario mencionar que se está iniciando un proceso de democratización y descentralización de las estructuras de salud, empezando por el SNS. En algunas áreas de salud, la comunidad organizada y los propios trabajadores de la salud se están integrando en el trabajo, a través de los Consejos Locales de Salud, base indispensable para llegar a un co-gobierno de hospitales, consultorios y niveles superiores del SNS mediante los Consejos Directivos, con amplias atribuciones ejecutivas. Para ello en las próximas semanas se enviará un proyecto de ley al Parlamento.

Unido al proceso de la democratización en las decisiones, se iniciará pronto una profunda descentralización técnico-administrativa, para facilitar las soluciones a nivel local de los propios problemas que se presentan. Al unir los esfuerzos mencionados de la autoridad local de la salud, de los trabajadores de la salud y de la población organizada. Estos aspectos están actualmente en plena discusión y análisis por parte de los trabajadores de la salud en sus diferentes agrupaciones gremiales (Colegio Médico, Federación de Profesionales y Técnicos, Federación de Trabajadores de la Salud, etc.) y en algunas áreas de Salud y Consultorios, por los propios representantes de la comunidad a través de los Consejos Locales de Salud. 